Center for Quality and Productivity Improvement

University of Wisconsin

610 Walnut Street

Madison, Wisconsin 53726

(608) 263-2520

(608) 263-1425 FAX

quality@engr.wisc.edu

Report No, 183

\title{
Design Evaluation of Multi-station Assembly Processes by Using State Space Approach
}

Yu Ding, Dariusz Ceglarek, Jianjun Shi

April 2000

The Center for Quality and Productivity Improvement cares about your reactions to our reports.

Please direct comments (general or specific) to: Reports Editor, Center for Quality and Productivity Improvement, 610 Walnut Street, Madison, WI 53726; (608) 263-2520.

All comments will be forwarded to the author(s). 


\section{Design Evaluation of Multi-station Assembly Processes by Using State Space Approach}

\author{
Yu Ding \\ Dept. of Industrial Engineering \\ Texas A\&M University \\ College Station, TX 77843-3131
}

\author{
Dariusz Ceglarek \\ Dept. of Industrial Engineering \\ University of Wisconsin - Madison \\ Madison, WI 53706
}

\section{Jianjun Shi}

Dept. of industrial and Operations Engineering

The University of Michigan

Ann Arbor, MI 48109

\section{ABSTRACT}

This paper considers the problem of evaluating and benchmarking process design configuration in a multi-station assembly process. We focus on the unique challenges brought by the multi-station system, namely, (1) a system level model to characterize the variation propagation in the entire process, and (2) the necessity to describe the system response to variation inputs at both global (system level) and local (station level and single fixture level) scales. State space representation is employed to recursively describe the propagation of variation in such a multi-station process, incorporating process design information such as fixture locating layout at individual stations and station-to-station locating layout change. Following the sensitivity analysis in control theory, a group of hierarchical sensitivity indices is defined and expressed in terms of the system matrices in the state space model, which are determined by the given process design configuration. Implication of these indices with respect to variation control is discussed and a three-step procedure of applying the sensitivity indices for selecting a better design and prioritizing the critical station/fixture is presented. We illustrate the proposed method using the group of sensitivity indices in design evaluation of the assembly process of a SUV (Sport Utility Vehicle) side panel.

\footnotetext{
* Corresponding author, Tel: (608)265-3457, Fax; (608)262-8454, Email; darek@engr.wisc.edu
} 


\section{NOMENCLATURE}

$\begin{array}{ll}\text { A } & \text { dynamic matrix } \\ \mathbf{B} & \text { input matrix } \\ \mathbf{C} & \text { observation matrix } \\ \text { KCC } & \text { Key Control Characteristics } \\ \text { KPC } & \text { Key Product Characteristics } \\ \mathbf{K}_{0} & \text { covariance matrix of part deviation } \\ \mathbf{K}_{p} & \text { covariance matrix of fixture deviation } \\ \mathbf{K}_{\mathbf{Y}} & \text { covariance matrix of KPCs } \\ \mathbf{K}_{\mathrm{c}} & \text { covariance matrix of uncertainty term } \varepsilon \\ \mathbf{P} & \text { fixture deviation vector } \\ \mathbf{W} & \text { weighting coefficient matrix } \\ \mathbf{X} & \text { part deviation vector } \\ \mathbf{Y} & \text { observation vector } \\ k & \text { station index } \\ n & \text { dimension of part deviation vector } \mathbf{X} \\ m_{k} & \text { dimension of fixture deviation } \mathbf{P}(k) \\ q_{k} & \text { dimension of observation vector } \mathbf{Y}(k) \\ \mathbf{\Phi} & \text { state transition matrix } \\ \varepsilon & \text { uncertainty term }\end{array}$

$\gamma(k)$ the model matrix of station $k$, equals to $\mathbf{C} \boldsymbol{\Phi}(N, k) \mathbf{B}(k)$,

$\gamma_{p}$ the $p^{\text {th }}$ column vector in $\gamma$

$\gamma_{q p}$ the $q^{\text {th }}$ element in column vector $\gamma_{p}$

$\sigma_{\text {cutput }}^{2}$ variance vector of KPCs on the final product

$\sigma_{k p}^{2} \quad$ variance of the $p^{\text {th }}$ locating feature at station $k$

$\sigma_{k}^{2} \quad$ variance vector of all fixtures at station $k, \sigma_{k}^{2}=\left[\begin{array}{lllll}\sigma_{k 1}^{2} & \cdots & \sigma_{k p}^{2} & \cdots & \sigma_{k m_{k}}^{2}\end{array}\right]^{\top}$

$\sigma_{\text {ingat }}^{2}$ variance vector of the entire process,



$\xi$ unmodeled process deviation

$\eta \quad$ additive sensor noise

\section{INTRODUCTION}

\subsection{Problem Description}

Multi-station assembly processes generally refer to those processes involving more than one workstation to manufacture a complex product. For example, the automotive body assembly process, consisting of up to 70 stations, is a typical multi-station assembly process to fabricate the structural frame of an automobile. Another example is the airplane wing/fuselage assembly process. Fixture locators are intensively used in those processes to provide part support and it relation to coordinate system and thus determine the dimensional accuracy of the final assembly (Ceglarek and Shi, 1995; Cunningham et al., 1996). As a result, the final product quality is greatly affected by the accumulation and propagation of variation caused by fixture elements on all assembly stations along the production stream.

Product quality is characterized by a group of features that could greatly affect the designed functionality and the level of customer satisfaction. In automotive industry, this group of 
critical features is known as KPC (Key Product Characteristics). The fixture locators are the dimensional control characteristics for product positioning and thus are the determining factors in achieving the required dimensional accuracy of KPCs. They are known as KCCs (Key Control Characteristics). In a multi-station process, the impact of $\mathrm{KCCs}^{\prime}$ variation on KPC's dimensional accuracy depends on process design configuration including the geometry of fixture locating layout on every station and the station-to-station locating layout change. Early design evaluation of multi-station assembly processes is very important for new product development and also for designing a robust manufacturing system to improve product quality.

The effective design evaluation methodology at the early design stage requires a set of indices, which are easy to interpret and comprehensive enough for the selection of robust process designs and quantifying the design improvement. The challenges related to the design evaluation of a multi-station process come from two aspects: (1) the set of benchmarking indices needs to address the system capability in response to variation inputs, suggesting that the set of indices should be represented in terms of the generic process/product design information and be independent of KCC variation inputs; (2) the comprehensive benchmarking of a multi-station process needs not only to compare the overall multi-station assembly system but also give the same insights related to critical assembly stations and individual KCC elements in the entire process.

\subsection{Related Work}

Design evaluation and comparative analysis of different designs have been studied by a number of researchers with consideration to various goals and objectives. Since product quality is taken as the indicator of process performance in this paper, only the design evaluation work aiming at improving quality and/or reducing variation will be discussed here.

We first distinguished between the imprecise description of design parameters and the analysis of manufacturing variability. The imprecision of parameters, which is a critical problem in the preliminary design stage, was modeled by Wood and Antonsson (1989) and Antonsson and Otto (1995) using fuzzy calculus. Their work seems similar to, but is in fact conceptually 
different from, the analysis of manufacturing variability. The methodology developed in their papers does not allow for the evaluation of product system performance, but rather allows for a better representation of imprecisely defined design parameters.

Process design evaluation with respect to the process response of manufacturing variability can be generally classified into two categories: (1) process capability analysis; and (2) sensitivity analysis. Process capability analysis (Montgomery, 1996) is based on the defined indices, most often using $\mathrm{C}_{\mathrm{p}}$ and $\mathrm{C}_{\mathrm{pk}}$, for a single or multiple design or quality characteristics. They are defined in terms of the statistics of production output to indicate the expected performance of a manufacturing process under the influence of variation and/or bias. Kazmer and Roser (1999) defined a capability index (called "robustness index" in their paper) for multiple simultaneous quality characteristics. Taguchi's Signal-to-Noise (S/N) ratio (Taguchi, 1986) can be classified into the same category, however, with a different interpretation of the $\mathrm{S} / \mathrm{N}$ value. This group of indices depends on variation input (input dependent) and is computed directly from the output data of KPCs. Because the KPC output is only available during full production, this group of inputdependent indices is not known in the design stage. Usually, they are used in the production stage to validate the design and identify possible process faults. However, it could be too late or too costly to modify the engineering design by then.

On the other hand design evaluation based on sensitivity analysis defines and develops input-independent ratios. Thus, it is a more effective evaluation approach during design stage. Sensitivity-based design analysis has been performed in many situations for different applications. One of the characteristics of sensitivity-based design evaluation is the characterization of product and process into Key Characteristics $(\mathrm{KC})$ : KPC and $\mathrm{KCC}$. The intuitive decomposition of the product and process into key characteristics was proposed by Ceglarek et al. (1994). They decomposed product into measurement locating points (MLP) which corresponds to KPC points in this paper; and the process into principal locating points (PLP) and clamping locating points (CLP). Thornton (1999a) proposed a mathematical framework for the KC process. A systematic $\mathrm{KC}$ flowdown was developed and an effectiveness measure was defined. A complex production 
system was broken into several layers corresponding to the product- $\mathrm{KC}$, part- $\mathrm{KC}$, and process- $\mathrm{KC}$. Actually, the $\mathrm{KC}$ defined in her paper has close relationship to the $\mathrm{KPC}$ and $\mathrm{KCC}$ used in this paper. $\mathrm{KPC}$ is equivalent to the product- $\mathrm{KC} /$ part- $\mathrm{KC}$ and $\mathrm{KCC}$ is the process- $\mathrm{KC}$. Figure 1 illustrates the variation propagation from $\mathrm{KCC}$ to $\mathrm{KPC}$. If the sensitivity analysis is performed to characterize the influence of variations of part-KPC on the quality of product-KPC, the corresponding variation model is developed within the product. Hence, the technique is labeled as "product-oriented". If the relationship between KCC and KPC is included in the variation model and sensitivity analysis, the technique is labeled as "process-oriented." This distinction is also shown in Fig. 1.



Figure 1. Process-oriented vs. product-oriented

Although $\mathrm{KCC}$ (process-KC) is included in the general framework of KC flowdown, only the product-oriented model and analysis is materialized for the door assembly case in Thomton (1999a). Similar product-oriented sensitivity analysis (some of them also include optimization) was performed toward different design goals by Whitney et al. (1994), Parkinson et al.(1993), Parkinson (1995), and Ceglarek and Shi (1998) among others.

Process-oriented sensitivity analysis is more difficult since the problem domain expands to include the process information and process/product interaction. Product variables (KPC) are more uniform, for instance, quantities included in an assembly can be all geometrical. Process variables $(\mathrm{KCC})$ are less uniform and could cover diversified physical parameters in a process design. When a process-oriented technique is discussed, it can be further divided into a single station approach (at the station level/machine level) and a multi-station approach (at the system level). Most of the process-oriented work has been done at the single station level. Thornton 
$(1999 \mathrm{~b}, 2000)$ included fixture elements as the KCC (process-KC) in the variation model and analysis of aircraft wing assembly. Similar station-level research work includes Chen et al. (1996), Cai et al. (1997), Wang (1999), and Soderberg and Carlson (1999).

The sensitivity analysis of multi-station processes is under-researched mainly due to the unavailability of a system level model which could link the KCC's variation to the KPC's quality. The challenges are also caused by the requirement of having comprehensive benchmarking at the system level, the station level, and a single KCC (fixture) level, as discussed in Section 1.1. Very few research papers were published in this area except for the paper of Suri and Otto (1999), which developed an Integrated System Model (ISM) for stretch forming process. They used a linearized predictive variation model integrated with an FEM (Finite Elements Method) models for stretch forming and heat treatment processes. The selective summary of the proposed methodologies is presented in Table 1.

Table 1. Comparative analysis of design evaluation methodologies

\begin{tabular}{|c|c|c|c|c|}
\hline \multicolumn{3}{|c|}{ Process capability analysis } & $\begin{array}{l}\text { Taguchi (1986), Montgomery (1996), } \\
\text { Kazmer and Roser (1999), }\end{array}$ & $\begin{array}{l}\text { Input } \\
\text { dependent }\end{array}$ \\
\hline \multirow{3}{*}{$\begin{array}{l}\text { Sensitivity- } \\
\text { based } \\
\text { Design } \\
\text { Analysis }\end{array}$} & \multicolumn{2}{|c|}{ Product-oriented } & $\begin{array}{l}\text { Parkinson et al. (1993), Whitney et al. (1994), } \\
\text { Parkinson (1995), Ceglarek \& Shi (1998), } \\
\text { Thornton (1999a) }\end{array}$ & \multirow{3}{*}{$\begin{array}{l}\text { Input } \\
\text { independent }\end{array}$} \\
\hline & \multirow{2}{*}{$\begin{array}{l}\text { Process- } \\
\text { oriented }\end{array}$} & $\begin{array}{l}\text { Station } \\
\text { level }\end{array}$ & $\begin{array}{l}\text { Chen et al. (1996), Cai et al. (1997), Wang } \\
\text { (1999), Soderberg \& Carlson (1999), } \\
\text { Thornton (1999b, 2000) }\end{array}$ & \\
\hline & & $\begin{array}{l}\text { System } \\
\text { level }\end{array}$ & $\begin{array}{l}\text { Stretch Forming Process : Suri and Otto (1999) } \\
\text { Multi-station Assembly Process: } \\
\text { To be developed in this paper }\end{array}$ & \\
\hline
\end{tabular}

\subsection{Proposed method}

The current literature shows a significant enhancement of engineering knowledge and practice in the area of sensitivity-based design evaluation methodologies. However, currently there is no systematically defined sensitivity index, which integrates key process and product characteristics and allows for comprehensive design evaluation and easy interpretation for multistation manufacturing processes. 
This paper presents a methodology for evaluating and benchmarking design configurations of multi-station assembly processes. The framework includes two main parts: (1) a system level model that describes the propagation and accumulation of $\mathrm{KCCs}$ ' variation and its impact on the quality of KPCs; and (2) a group of sensitivity indices defined hierarchically at three levels (system/station/fixture) for the comprehensive characterization of relationships between multiple $\mathrm{KCCs}$ and multiple KPCs. By using these indices, various process designs can be compared to indicate a more robust design configuration. The pareto analysis identifying the critical station (or fixture element) contributing most to the variation of KPCs can be conducted as well.

This paper is divided into five sections. Section 2 presents the state space model for a multi-station assembly process. Section 3 defines the system sensitivity indices and derives their expressions in terms of process/product design parameters, followed by the discussion on a process design evaluation procedure. In Section 4, an industrial case study is presented to illustrate the proposed sensitivity indices and design evaluation procedure. Finally, the methodology is summarized and its implications are discussed in Section 5. The developed design evaluation indices are presented in the context of automotive body assembly processes for which data and process knowledge are available. However, we feel that this methodology could be applied to any multistage manufacturing process as long as it can be modeled using the framework of state space representation.

\section{STATE SPACE MODEL OF VARIATION PROPAGATION}

The state space modeling of variation propagation for multi-station assembly processes will be presented using, as a case in point, the automotive body assembly process. A generic description of the automotive body assembly process was presented in Ceglarek et al. (1994) and Ceglarek and Shi (1995). We will illustrate our method using the assembly process of the side frame panel of a Sports Utility Vehicle (SUV) body. 
This assembly process, shown in Fig. 2, is conducted at three assembly stations (Station I, II, III) and the product is inspected at the measurement station. The final subassembly innerpanel-complete (Fig. 2(c)) consists of four components: A-pillar, B-pillar, rail roof side panel, and rear quarter panel. At Station I (Fig. 2(a)), the A-pillar and the B-pillar are joined together. The subassembly "A-pillar+B-pillar" is welded with the rail roof side panel at Station II (Fig. 2(b)). The subassembly of the first three panels is then assembled with the rear quarter panel at Station III (Fig. 2(c)). Finally, measurements are taken at KPC points (marked in Fig. 2(d) as $\mathrm{M}_{1}-\mathrm{M}_{10}$ ) by using off-line or in-line measurement systems such as CMM (Coordinate Measuring Machine) or OCMM (Optical CMM).

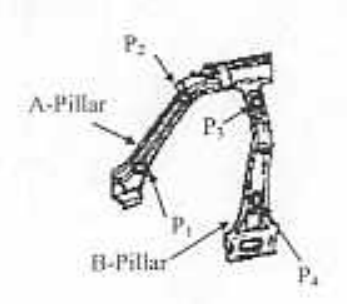

(a) Station 1

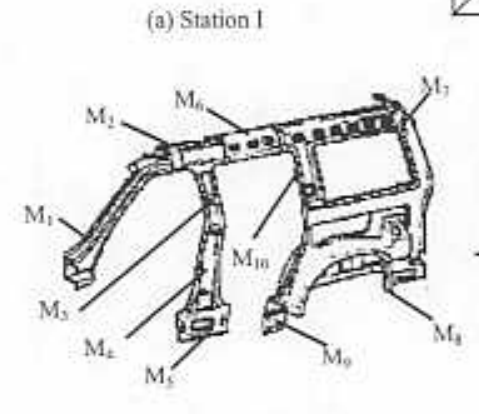

(d) Measurement: KPC Points

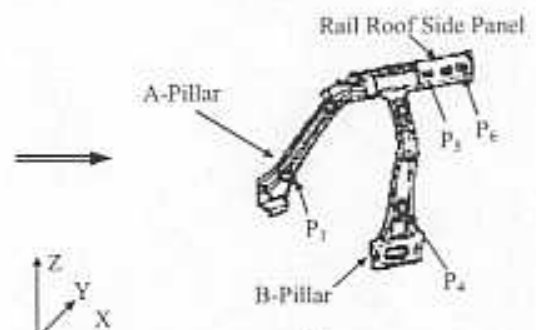

(b) Station II

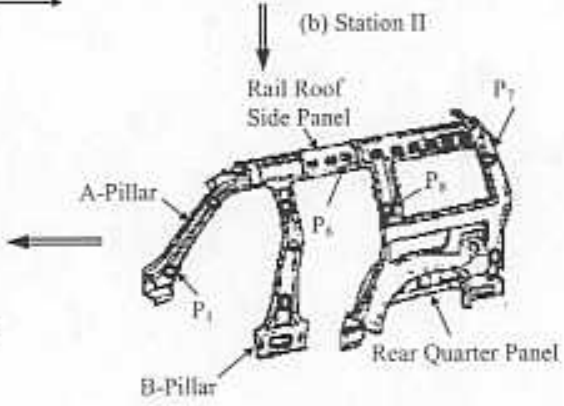

(c) Station III

Figure 2. Assembly process of the side aperture panel of a SUV

On each assembly station, the part/subassembly is positioned by a set of n-2-1 fixtures, constituting a 4-way locating pin constraining part motion in both $\mathrm{X}$ and $\mathrm{Z}$ directions, a 2-way locating pin constraining part motion in only $\mathrm{Z}$ direction, and several $\mathrm{NC}$ blocks constraining part motion in $\mathrm{Y}$ direction. The set of fixture locators supporting one workpiece is denoted as $\left\{\mathrm{P}_{4 \text { way }}\right.$, $\left.\mathrm{P}_{2 \text { way, }} \mathrm{NC}_{i}, i=1, \ldots, n_{c}\right\}$. An example of a 3-2-1 fixture layout is shown in Fig. 3. For the sake of simplicity, this paper presents the analysis of dimensional variation in the 2-D X-Z plane as shown 
in Figs. 2 and 3. The fixture locators marked as NC blocks will then be assumed to have no error and be positioned at their design nominal positions. Hence, the fixture set is simplified as $\left\{\mathrm{P}_{\text {away, }}\right.$ $\left.\mathrm{P}_{2 \text { way }}\right\}$.

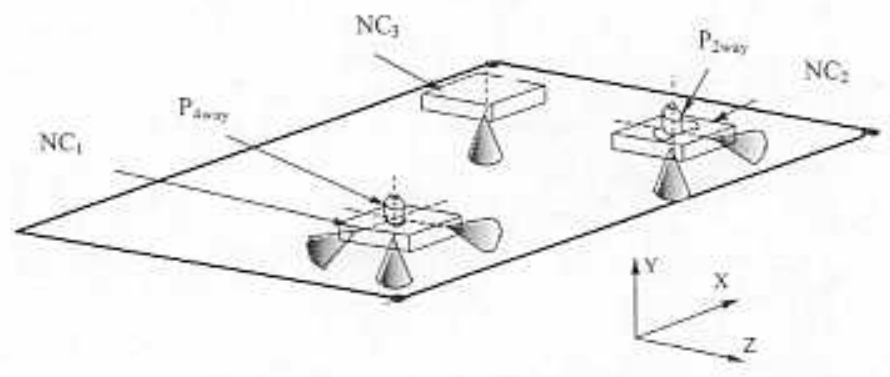

Figure 3. A schematic diagram of 3-2-1 fixture layout

$\mathrm{P}_{1}-\mathrm{P}_{8}$ in Fig. 2 (a) - (c) represent the principal locating points (PLPs) of a workpiece (a single part or a subassembly). They correspond to the pin-hole pairs used to position the workpiece on a station. After two parts are assembled, there are more than one possible set of PLPs to be used for positioning the subassembly. For example, at Station II, there are two sets of PLPs $\left\{\mathrm{P}_{1}, \mathrm{P}_{2}\right\}$ and $\left\{\mathrm{P}_{3}, \mathrm{P}_{4}\right\}$ on the subassembly "A-pillar+B-pillar". In order to position this subassembly, any combination of the following four combinations can be used - $\left\{\mathrm{P}_{1}, \mathrm{P}_{2}\right\},\left\{\mathrm{P}_{3}, \mathrm{P}_{4}\right\}$, $\left\{\mathrm{P}_{1}, \mathrm{P}_{4}\right\}$, and $\left\{\mathrm{P}_{3}, \mathrm{P}_{2}\right\}^{*}$. The fixture locating layout changes when a subassembly is transferred to the following station. This locating layout change has significant impact on the propagation of dimensional variation in a multi-station assembly process (Shiu et al., 1996). We use the following notation to indicate the fixture locating layout on individual stations and the station-tostation locating layout change of the assembly process in Fig. 2:

$$
\left\{\left\{\mathrm{P}_{1}, \mathrm{P}_{2}\right\},\left\{\mathrm{P}_{3}, \mathrm{P}_{4}\right\}\right\}_{1} \rightarrow\left\{\left\{\mathrm{P}_{1}, \mathrm{P}_{4}\right\},\left\{\mathrm{P}_{5}, \mathrm{P}_{6}\right\}\right\}_{n} \rightarrow\left\{\left\{\mathrm{P}_{1}, \mathrm{P}_{6}\right\},\left\{\mathrm{P}_{7}, \mathrm{P}_{8}\right\}\right\}_{m} \rightarrow\left\{\left\{\mathrm{P}_{1}, \mathrm{P}_{8}\right\}\right\}_{\mathrm{iv}}
$$

where the arrow represents the assembly transition from one station to another and the notation in each bracket follows $\left\{\left\{\right.\right.$ fixture set for the $1^{\text {st }}$ workpiece $\}$, \{fixture set for the $2^{\text {nd }}$ workpiece $\left.\}, \ldots\right\}$. For example, $\left\{\left\{\mathrm{P}_{1}, \mathrm{P}_{4}\right\},\left\{\mathrm{P}_{5}, \mathrm{P}_{6}\right\}\right\}_{n}$ means that the first workpiece on Station $I$, the subassembly of A-pillar and B-pillar, is located by $\mathrm{P}_{1}$ and $\mathrm{P}_{4}$, and the second workpiece on Station II, the rail roof

\footnotetext{
- In the notation $\left\{\mathrm{P}_{\mathrm{i}}, \mathrm{P}_{\mathrm{j}}\right\}, \mathrm{P}_{\mathrm{i}}$ is always defined as a 4-way pin/PLP and $\mathrm{P}_{\mathrm{i}}$ as a 2-way pin/PLP.
} 
side panel, is located by $\mathrm{P}_{5}$ and $\mathrm{P}_{6}$ (Fig. 2(b)). At the fourth station, i.e., the measurement station, one pair of locators $\left\{\mathrm{P}_{1}, \mathrm{P}_{8}\right\}$ is used to position the final subassembly when measurements are taken at $\mathrm{KPC}$ points.

The modeling of fixture-related variation propagation in multi-station assembly processes has been studied by Jin and Shi (1999) and Ding et al. (2000a). Two major variation contributors are identified: one is the fixture variation at each single station (Fig. $4(\mathrm{a})$ ), where $\delta \mathrm{P}_{2}(\mathrm{z})$ is the deviation in Z-direction at locator $\mathrm{P}_{2}$, and the second, the reorientation-induced variation when an assembly is transferred to another station (Fig. 4(b)). The first factor, the fixture variation on individual stations, is affected by the geometry of fixture locating layout, i.e., the coordinates of fixture locators. The second factor, the reorientation-induced variation, is affected by the stationto-station change of fixture locating layouts.



(a)



(b)

Figure 4. Variation induced at a single station and across stations

These two variation contributors in an $\mathrm{N}$-station assembly process (Fig. 5) and their propagation throughout the entire process can be modeled by using a state space representation (Jin and Shi, 1999; Ding et al., 2000a). We use the following notations: $\mathbf{X}(k) \in R^{n \times 1}$ is the accumulated part deviation up to station $k ; \mathrm{P}(k) \in R^{m_{k} \times 1}$ is the fixture deviation contributed from station $k ; \mathrm{Y}(k) \in R^{q_{k} \times 1}$ is the measurement deviation observed at station $k$; subscripts $n, m_{k}$, and $q_{k}$ are dimensions of the three vectors, respectively; $\xi$ is the unmodeled process deviation such as the higher order terms resulted from linearization and/or other variation sources, and $\boldsymbol{\eta}$ is the additive sensor noise; $\xi$ and $\eta$ are assumed mutually independent. $\sigma_{k p}^{2}, \sigma_{\text {inpwit }}^{2}$, and $\sigma_{\text {oarput }}^{2}$ describe the 
variance of a single fixture KCC, the entire KCC points (of multiple stations and fixtures), and KPC points, respectively. They will be explained in Section 3.



Figure 5. Diagram of an assembly process with $N$ stations

The basic idea of developing the state space model is to consider the multi-station process as a sequential dynamic system but replace the time index in the traditional state space model with a station index. The state space model includes two equations:

$$
\begin{aligned}
& \mathbf{X}(k)=\mathbf{A}(k-1) \mathbf{X}(k-1)+\mathbf{B}(k) \mathbf{P}(k)+\boldsymbol{\xi}(k), k=1,2, \ldots, N \\
& \mathbf{Y}(k)=\mathbf{C}(k) \mathbf{X}(k)+\eta(k),\{k\} \subset\{1,2, \ldots, N\}
\end{aligned}
$$

where the first equation, known as the state equation, suggests that the part deviation at station $k$ is influenced by the accumulated deviation up to station $k-1$ and the deviation contribution at station $k$; the second equation is the observation equation.

System matrices A, B, and C are determined by the process/product design. Matrix A, known as the dynamic matrix, characterizes the assembly reorientation during part transfer between stations. In other words, A depends on the station-to-station locating layout change in a production stream. Matrix B is the input matrix which determines how the fixture deviation affects part deviation, depending on the geometry of a fixture layout. Matrix $\mathbf{C}$ contains the information about sensor positions on product, which are often the selected KPC points during design stage. The index of the observation equation (Eq. 2 ) is normally a subset of $\{1,2, \ldots, N\}$ since KPCs are not measured on all stations. Usually, KPCs are selected on the final product in a design problem, as it corresponds to the end-of-line observation in the presented earlier SUV side 
frame assembly process. In such case, $k=N$ in Eq. (2), and thereby, we can obtain the following input-output relationship:

$$
\mathbf{Y}=\sum_{k=1}^{N} \gamma(k) \mathbf{P}(k)+\gamma(0) \mathbf{X}(0)+\varepsilon
$$

where

$$
\begin{aligned}
& \gamma(k)=\mathbf{C} \Phi(N, k) \mathbf{B}(k) \quad \text { and } \quad \gamma(0)=\mathbf{C} \Phi(N, 0) \\
& \varepsilon=\sum_{k=1}^{N} \mathbf{C} \Phi(N, k) \xi(k)+\eta \\
& \Phi(N, k)=\mathbf{A}(N-1) \mathbf{A}(N-2) \cdots \mathbf{A}(k) \text { and } \boldsymbol{\Phi}(k, k)=\mathbf{I}^{n \times n}
\end{aligned}
$$

and the index $N$ for $\mathbf{Y}, \mathbf{C}$, and $\eta$ can be dropped without ambiguity. Here, $\mathbf{X}(0)$ corresponds to the initial part deviation condition resulting from the precedent stamping process. The input-output covariance relationship could be obtained from Eq. (3)

$$
\mathbf{K}_{\mathrm{Y}}=\sum_{k=1}^{N} \gamma(k) \mathbf{K}_{\mathrm{P}}(k) \gamma^{\mathrm{T}}(k)+\gamma(0) \mathbf{K}_{0} \gamma^{\top}(0)+\mathbf{K}_{\varepsilon}
$$

This relationship expresses the variation of KPCs $\left(\mathrm{K}_{\mathrm{Y}}\right)$ in terms of the variation of KCCs $\left(\mathbf{K}_{\mathrm{p}}(k)\right)$ at all stations, the part stamping variation $\left(\mathbf{K}_{\mathrm{q}}\right)$, and the noise variation $\left(\mathbf{K}_{\mathrm{e}}\right)$. Since the goal of this paper is to benchmark fixture design configuration, we will focus our analysis on the variation of $\mathrm{KCCs}\left(\mathrm{K}_{\mathrm{P}}(k)\right)$. The impact of part variation and noise variation is not discussed in this paper. Therefore, we can simplify Eq. (7) and only keep terms related to KCCs' variation

$$
\mathbf{K}_{\boldsymbol{\gamma}}=\sum_{k=1}^{N} \gamma(k) \mathbf{K}_{\mathrm{p}}(k) \gamma^{\top}(k)
$$

where $\gamma(k)=\mathbf{C} \Phi(N, k) \mathbf{B}(k)$ incorporates all process design information. The $\gamma(k)$ is also called the model matrix of station $k$.

This station-indexed state space model is a different form of the standard kinematic analysis model of multi-station assembly processes. Recently, other system level models were developed, describing variation propagation in manufacturing systems. Variation System Analysis (VSA, 1998) is a descriptive commercial software, employing the Variation Simulation Language (VSL) to describe an assembly process and the variation flow that is involved in it. Mantripragada and Whitney (1999) used a state transition model to describe the variation stack-up 
among parts in an assembly. In their work, KCCs such as fixture elements are assumed free of variation. Lawless et al. (1999) and Agrawal et al. (1999) adopted a station-indexed AR(1) model to investigate variation transmission in both machining and assembly processes. Their model is a statistical model, and the model parameters have to be estimated through production data that are not yet available during design stage. Suri and Otto (1999) and Suri et al. (1999) used the Integrated System Model (ISM) to characterize the propagation of variation in stretch forming and MIG welding processes, respectively. All of the above models except the VSA model to be analytical. These analytical models have similar mathematical expressions as the presented state space model. Table 2 presents a short summary of all aforementioned models. Based on Table 2 , the state space model is concluded to be better suited for describing a system level fixture design in a multi-station assembly process.

Table 2. Comparison of system level variation models

\begin{tabular}{|l|l|l|l|l|}
\hline \multicolumn{1}{|c|}{ Model Name } & \multicolumn{1}{|c|}{ Literature } & Model Type & $\begin{array}{l}\text { Product-oriented vs. } \\
\text { Process-oriented }\end{array}$ & Problem domain \\
\hline State Space Model & $\begin{array}{l}\text { Jin and Shi (1999), } \\
\text { Ding et al. (2000a) }\end{array}$ & $\begin{array}{l}\text { Physical \& } \\
\text { analytical }\end{array}$ & $\begin{array}{l}\text { Process-oriented } \\
\text { (KCC } \text { fixture) }\end{array}$ & $\begin{array}{l}\text { multi-station } \\
\text { assembly }\end{array}$ \\
\hline $\begin{array}{l}\text { State Transition } \\
\text { Model }\end{array}$ & $\begin{array}{l}\text { Mantripragada \& } \\
\text { Whitney (1999) }\end{array}$ & $\begin{array}{l}\text { Physical \& } \\
\text { analytical }\end{array}$ & Product-oriented & assembly \\
\hline AR(1) Model & $\begin{array}{l}\text { Lawless } \text { et al. (1999), } \\
\text { Agrawal } \text { et al. (1999) }\end{array}$ & $\begin{array}{l}\text { Statistical \& } \\
\text { analytical }\end{array}$ & Process-oriented & $\begin{array}{l}\text { machining, } \\
\text { assembly }\end{array}$ \\
\hline $\begin{array}{l}\text { Integrated System } \\
\text { Model }\end{array}$ & $\begin{array}{l}\text { Suri and Otto (1999), } \\
\text { Suri et al. (1999) }\end{array}$ & $\begin{array}{l}\text { Physical \& } \\
\text { analytical }\end{array}$ & Process-oriented & $\begin{array}{l}\text { stretch forming, } \\
\text { MIG welding }\end{array}$ \\
\hline VSA & VSA manual (1998) & $\begin{array}{l}\text { descriptive, } \\
\text { numerical }\end{array}$ & Process-oriented & assembly \\
\hline
\end{tabular}

\section{SENSITIVTTY-BASED DESIGN EVALUATION INDICES}

The state space model presented in Section 2 provides the basis for process design evaluation in the following ways: (i) The variation propagation model, as shown in Eq. (8), describes the relationship between $\mathrm{KPC}$ variations and $\mathrm{KCC}$ input variations. The potential evaluation index, namely, the ratio of $\mathrm{KPC}$ variations over $\mathrm{KCC}$ variations can be expressed in terms of the model matrix $\gamma(k)$ defined in Eq. (4). (ii) The process design information is 
embedded in system matrices A, B, and C, which are determined by the station-to-station locating layout change, the geometry of fixture locating layout on individual stations, and the selection of KPCs, respectively. The model matrix $\gamma(k)$ incorporates the design information included in those system matrices. In short, the above two items (i) and (ii) imply that the state space model integrates a rich process design information, serving as the basis for the development of desirable design evaluation indices. It can be also noted that the state space system model describes a linear "time varying" stochastic process if the station index $k$ is compared to the time index in a dynamic system. In another word, the state space model has the advantage of matching well with the conventional control theory. The evaluation of multi-station assembly process design can then be conducted in parallel to the sensitivity analysis of a dynamic system.

A single design evaluation index is inadequate to describe critical aspects of variation propagation in a multi-station assembly system. The index based on the entire variation input and output of the system characterizes the overall process performance, however, it does not provide any detailed information about an individual station or a single fixture. On the other hand, the index based on the variation input and output of a simple fixture characterizes the performance of a single fixture during production, but it does not provide the joint effect of multiple variation inputs at the system level. Therefore, in this paper, a group of hierarchical multi-level indices is developed to capture critical aspects of the variation behavior of a multi-station assembly process. Furthermore, these multi-level indices are expressed in terms of the critical process design characteristics and are independent of variation inputs since it is the design configuration that needs to be evaluated rather than the transmitted variation.

For the $\mathrm{N}$-station assembly process shown in Fig. 5 , the KPC variation is denoted as a variance vector $\sigma_{\text {outpur }}^{2}$, which elements are the diagonal elements of $\mathbf{K}_{\mathrm{Y}}$, i.e., $\sigma_{\text {output }}^{2}=\operatorname{diag}\left(\mathbf{K}_{\mathrm{Y}}\right)$. The KCC variation inputs are decomposed into three levels. Variation $\sigma_{k p}^{2}$ of at the single fixture level stands for the variance of the $p^{\text {th }}$ locating feature at station $k$. Variation vector $\sigma_{k}^{2}$ at a single station level is denoted as $\sigma_{k}^{2}=\left[\begin{array}{lllll}\sigma_{k 1}^{2} & \cdots & \sigma_{k p}^{2} & \cdots & \sigma_{k m_{4}}^{2}\end{array}\right]^{\mathrm{T}}$. It is easy to verify that 
$\sigma_{k}^{2}=\operatorname{diag}\left(\mathrm{K}_{\mathrm{p}}(k)\right)$. Variation vector $\boldsymbol{\sigma}_{\text {inpui }}^{2}$ represents the variation inputs of the entire process and is defined as $\sigma_{\text {input }}^{2}=\left[\begin{array}{lllll}\sigma_{1}^{2 T} & \cdots & \sigma_{k}^{2} & \cdots & \sigma_{\mathrm{N}}^{2}\end{array}\right]^{\mathrm{T}}$.

The proposed sensitivity analysis for design evaluation defines: (1) how the system responds to certain variation inputs, (2) which variation source contributes most to the final product variation, and/or (3) how the process parameters account most for the variation propagation. As such, the sensitivity indices are similar to the system gains in the conventional control theory. Appropriate measure is introduced to represent the process sensitivity as the gain of a Multiple-Input-Multiple-Output (MIMO) system. Three-level sensitivity indices are defined to facilitate the description of the system behavior of a multi-station assembly process: single fixture level, station level with multi-fixture, and system level (multi-station).

Definition I. The sensitivity-based design evaluation index at the fixture level, denoted as $S_{k p}$ is defined as

$$
S_{k y}=\frac{\left\|\mathbf{W} \boldsymbol{\sigma}_{\text {outprur }}^{2}\right\|_{2}}{\sigma_{k p}^{2}}
$$

where weighting coefficient $\mathbf{W}$ determines the relative importance of $\mathrm{KPC}$ variances and $\|-\|_{2}$ is the Euclidean norm. $S_{k p}$ index indicates how the $p^{\text {th }}$ locating feature at station $k$ contributes to the KPC variations. At this level, $S_{k p}$ in fact, corresponds to the gain of a Single-Input-MultipleOutput (SIMO) system.

Definition II. The sensitivity-based design evaluation index at the station level, denoted as $S_{k}$ is defined as

$$
S_{k}=\sup _{\sigma_{i}^{2}} \frac{\left\|\mathbf{W} \boldsymbol{\sigma}_{\text {olutput }}^{2}\right\|_{2}}{\left\|\sigma_{k}^{2}\right\|_{2}}
$$

$S_{k}$ index indicates how the fixture elements on station $k$ jointly affect the KPC variation. It is a MIMO-type gain since each station contains multiple fixtures. Station-level sensitivity index $S_{k}$ identifies the critical station contributing most to the KPC variation.

Definition III. The sensitivity-based design evaluation index at the system level, denoted as $S_{o}$ is defined as 


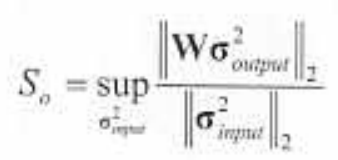

$S_{\rho}$ index indicates the system capacity to amplify or suppress the input variations. $S_{\odot}$ index is also a MIMO-type gain.

The above defined indices $S_{k p}, S_{k}$, and $S_{o}$ are the ratios of the KPC variation over the KCC variation. Consider $\left\|\mathrm{W} \sigma_{\text {oumput }}^{2}\right\|_{2}$ as the indicator of the KPC variation level. Indices $S_{k p}, S_{k}$, and $S_{o}$ are the values of KPC variation given a unit KCC variation input. The unit of $\mathrm{KCC}$ variation is different for the three indices: for a single fixture, a unit $\mathrm{KCC}$ variation is equivalent to $\sigma_{k p}^{2}=1$; for a station, a unit KCC variation is the joint effect from the multiple fixtures, defined as $\left\|\sigma_{k}^{2}\right\|_{2}=1$; for the entire system, a unit KCC variation is the combining effect from the multiple stations, defined as $\left\|\sigma_{\text {inyur }}^{2}\right\|_{2}=1$. A sensitivity index less than 1 means that the KPC variation level can become lower than the $\mathrm{KCC}$ variation level. On the contrary, a sensitivity index larger than 1 implies that the system amplifies the input variation. Most of the multi-station systems will end up with the sensitivity greater than 1 . Nonetheless, the smaller sensitivity value suggests a less variation-sensitive system which is preferable. Therefore, using and comparing this group of indices, a robust process configuration can be selected, and the sensitive station and fixture can be identified and prioritized.

Next, the indices $S_{k p}, S_{k}$, and $S_{o}$ are expressed in terms of the model matrix $\gamma$ so that they are made input-independent. The relationships are revealed by the following Lemma and Theorems.

Lemma. If the KCC variation inputs in Fig. 5 are uncorrelated, the KPC variance vector $\sigma_{\text {murgut }}^{2}$ can be represented as a linear combination of the vector $\sigma_{k}^{2}$. The expression can be represented as

$$
\boldsymbol{\sigma}_{\text {oupput }}^{2}=\sum_{k=1}^{N}\left[\gamma^{2}(k)\right] \cdot \sigma_{k}^{2}
$$

where $\left[\gamma^{2}(k)\right]$ represents a matrix in which each element is the square of the corresponding element in matrix $\gamma(k)$, i.e., 


$$
\left[\gamma^{2}\right]=\left[\begin{array}{cccc}
\gamma_{11}^{2} & \gamma_{12}^{2} & \cdots & \gamma_{L m}^{2} \\
\gamma_{21}^{2} & \gamma_{22}^{2} & \cdots & \gamma_{2 m}^{2} \\
\vdots & \vdots & \ddots & \vdots \\
\gamma_{q 1}^{2} & \gamma_{\psi 2}^{2} & \cdots & \gamma_{u m}^{2}
\end{array}\right]
$$

Proof. see Appendix I.

Given that the elements of $\mathbf{P}(k)$, the fixture deviations at station $k$, are mutually uncorrelated, the above Lemma holds true for the variation propagation in a multi-station assembly process. The following theorems present the expressions for three sensitivity indices, starting with the fixture-level index $S_{\text {hp }}$.

According to the definition of $S_{k p}$ index, it is assumed that there is only a single variation source (rather than multiple simultaneous sources) in the entire process at each time.

Theorem I. The fixture-level sensitivity index $S_{k p}$ for the $p^{\text {th }}$ PLP on station $k$ can be expressed as

$$
S_{i p}=\left\|\mathbf{W} \cdot \gamma_{p}^{2}(k)\right\|_{2}
$$

Proof. When only a single locating feature is deviated from its nominal position, the only nonzero vector in all $\mathrm{KCC}$ inputs is $\sigma_{k}^{2}$, which contains one nonzero element $\sigma_{k p}^{2}$, i.e.,

$$
\sigma_{k}^{2}=\left[\begin{array}{lllll}
0 & \cdots & \sigma_{k p}^{2} & \cdots & 0
\end{array}\right]^{T}
$$

Substituting Eq. (15) into Eq. (12) yields

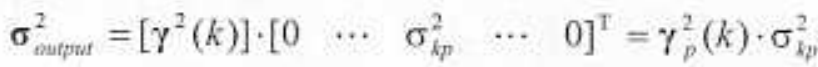

Substituting Eq. (16) into the definition of the fixture sensitivity (Eq. (9)) leads to Eq. (14).

The second index is the station sensitivity index $S_{k}$. It is assumed that only one station has variation inputs at a time. But within each station, more than one fixture element could contribute to $\sigma_{\text {outrour }}^{2}$ simultaneously.

Theorem 2 . The station-level sensitivity index $S_{k}$ can be expressed as

$$
S_{k}=\left\|\mathbf{W} \cdot\left[\gamma^{2}(k)\right]\right\|_{2}
$$

Proof. The proof is very straightforward. If there is only station $k$ having variation inputs, then the vector $\sigma_{i}^{2}$ is a zero vector if $i \neq k$. Following Eq. (12), we have 


$$
\sigma_{\text {outpuit }}^{2}=\left[\gamma^{2}(k)\right] \cdot \sigma_{k}^{2}
$$

Substituting it into the definition of station sensitivity gives

$$
S_{k}=\sup _{\sigma_{i}^{2}} \frac{\left\|\mathbf{W} \cdot\left[\gamma^{2}(k)\right] \cdot \boldsymbol{\sigma}_{k}^{2}\right\|_{2}}{\left\|\sigma_{k}^{2}\right\|_{2}}=\left\|\mathbf{W} \cdot\left[\gamma^{2}(k)\right]\right\|_{2}
$$

The above equality holds based on the definition of 2-norm of a matrix, which is the largest singular value of the matrix (Chen, 1984).

System-level sensitivity will consider all possible combinations of multiple KCC variation inputs - within a station and/or cross stations. Thus, it represents the overall sensitivity level of a process as to the KCC variation inputs.

Theorem 3. The system-level sensitivity index $S_{0}$ can be expressed as

$$
S_{o}=\| \mathbf{W} \cdot\left[\begin{array}{llll}
\gamma^{2}(1) & \gamma^{2}(2) & \cdots & \gamma^{2}(N)
\end{array} \|_{2}\right.
$$

Proof. The input variance vector $\boldsymbol{\sigma}_{\text {inpur }}^{2}$ is the combination of variance vectors at all stations. Rearranging Eq. (12) in Lemma as

$$
\sigma_{\text {ouput }}^{2}=\left[\begin{array}{llll}
\gamma^{2}(1) & \gamma^{2}(2) & \cdots & \gamma^{2}(N)
\end{array}\right] \cdot\left[\begin{array}{c}
\sigma_{1}^{2} \\
\sigma_{2}^{2} \\
\vdots \\
\sigma_{N}^{2}
\end{array}\right]=\left[\begin{array}{lllll}
\gamma^{2}(1) & \gamma^{2}(2) & \cdots & \gamma^{2}(N)
\end{array}\right] \cdot \sigma_{\text {injur }}^{2}
$$

According to the definition of $S_{0}$ and based on the same argument as that in the proof of Theorem 2, Eq. (20) can be obtained.

It is also possible to define the station and system sensitivity indices using the fixture sensitivity index, that is, choosing the largest fixture sensitivity index within a station or in a process as the station and system indices, respectively. Under this definition, these new indices could represent process response to a single variation input, whereas the proposed indices in this paper (Eqs. (10) and (11)) describe the joint effect of multiple simultaneous variation inputs. The results are different using the two sets of definitions. The selection between both sets of indices depends on the specific requirements of applications. 
Sensitivity-based design evaluation using the aforementioned analytical approach is more generic and comprehensive than numerical methods such as VSA software. First, it is numerically efficient since the time-consuming Monte Carlo simulation can be avoided in obtaining these indices. Hence, as long as the system matrices A, B, C are available, the calculation of three-level sensitivity indices for a large-scale system could be finished within seconds of CPU time. Second, the numerical methods can calculate the fraction of variation on the final product contributed from various individual inputs, which corresponds to the fixture sensitivity index defined above. Thus, this is actually a SIMO- rather than a MIMO-type of index. In general, the MIMO-type index is difficult to obtain using numerical methods since an exhaustive search of variation inputs need to be performed to find the supremum. Third, the proposed analytical models and sensitivity expressions provide the basis for further design optimization research, which is our ongoing work. Redesigning the manufacturing process could result in a decrease of the system sensitivity and an increase in its robustness to external noises. In contrast, the numerical methods can do design evaluation for the given process parameters but fall short of finding the optimal process configuration.

Based on the proposed indices, system sensitivity analysis can be conducted in three steps (Fig. 6): 1) When there is a need for benchmarking or comparison of alternative process design configurations, the sensitivity analysis can be performed at the system level to reveal the optimal design configuration that yields the lowest process sensitivity index; 2) Within that design, a station level sensitivity study can identify the critical stations in the process which contribute most to the KPC variation; 3) Using fixture sensitivity index will further isolate the largest variation input within a critical station. The three-step sensitivity analysis can help to select better process design and set up proper priority policy to focus on the most critical variation sources.

The dimensional quality of the KPC points on the final product depends on both $\mathrm{KCC}$ variation inputs and the sensitivity of the assembly system. The KCC variation level is limited by its tolerance range. The overall quality improvement of the assembly system is based on two steps: (1) System sensitivity-based design improvement to reduce system sensitivity (or increase 
system robustness) to dimensional variation. This step can be realized by following the method developed in this paper (Fig. 6). (2) Optimal KCC tolerance allocation to satisfy the quality requirement of $\mathrm{KPC}$ points, presented as the process-oriented tolerancing (Ding et al., 2000b). The results of process-oriented tolerancing verify the intuitive understanding that the tolerance should be tightened for those sensitive fixture locators and relaxed for the insensitive ones so that the overall manufacturing cost is reduced.



Figure 6. Three-step system sensitivity analysis

\section{EXAMPLE}

The assembly process of the SUV side panel, discussed in Section 2, is used to illustrate the concepts of sensitivity analysis and demonstrate the proposed design evaluation methodology. In addition to PLPs $\mathrm{P}_{1}-\mathrm{P}_{8}$ used in the assembly process, there is an extra locating hole $\mathrm{P}_{9}$ (Fig. 7) on the rear quarter panel which can be used to first position this panel on Station III, and then the whole subassembly on the measurement station. The nominal design positions of the fixture locators (PLPs) and KPC points in 2-D (X-Z coordinates) are given in Table 3 and Table 4, respectively.

Table 3. Coordinates of fixture locators (PLPs) from Fig. 7. (Units: mm)

\begin{tabular}{|c|c|c|c|c|c|}
\hline PLP & $\mathrm{P}_{1}$ & $\mathrm{P}_{2}$ & $\mathrm{P}_{3}$ & $\mathrm{P}_{4}$ & $\mathrm{P}_{5}$ \\
\hline$(\mathrm{X}, \mathrm{Z})$ & $(367,8,906.05)$ & $(667.47,1295.35)$ & $(1301,1368.89)$ & $(1272.73,537.37)$ & $(1470.71,1640.40)$ \\
\hline $\mathrm{PLP}$ & $\mathrm{P}_{6}$ & \multicolumn{2}{|c|}{$\mathrm{P}_{7}$} & $\mathrm{P}_{8}$ & $\mathrm{P}_{9}$ \\
\hline$(\mathrm{X}, \mathrm{Z})$ & $(1770.50,1702.62)$ & $(2941.42,1691.31)$ & $(2120.32,1402.83)$ & $(3026.25,950.30)$ \\
\hline
\end{tabular}


Table 4. Coordinates of KPCs from Fig. 2(d). (Units: mm)

\begin{tabular}{|c|c|c|c|c|c|}
\hline $\mathrm{KPC}$ & $\mathrm{M}_{1}$ & $\mathrm{M}_{2}$ & $\mathrm{M}_{3}$ & $\mathrm{M}_{4}$ & $\mathrm{M}_{5}$ \\
\hline $\mathrm{X}, \mathrm{Z})$ & $(271.50,905)$ & $(565.7,1634.7)$ & $(1289.7,1227.5)$ & $(1306.5,633,5)$ & $(1244.5,85)$ \\
\hline $\mathrm{KPC}$ & $\mathrm{M}_{6}$ & $\mathrm{M}_{7}$ & $\mathrm{M}_{8}$ & $\mathrm{M}_{9}$ & $\mathrm{M}_{10}$ \\
\hline$(\mathrm{X}, \mathrm{Z})$ & $(1604.5,1781.8)$ & $(2884.8,1951.5)$ & $(2743.5,475.2)$ & $(1838,4,226.3)$ & $(1979.8,1459.4)$ \\
\hline
\end{tabular}

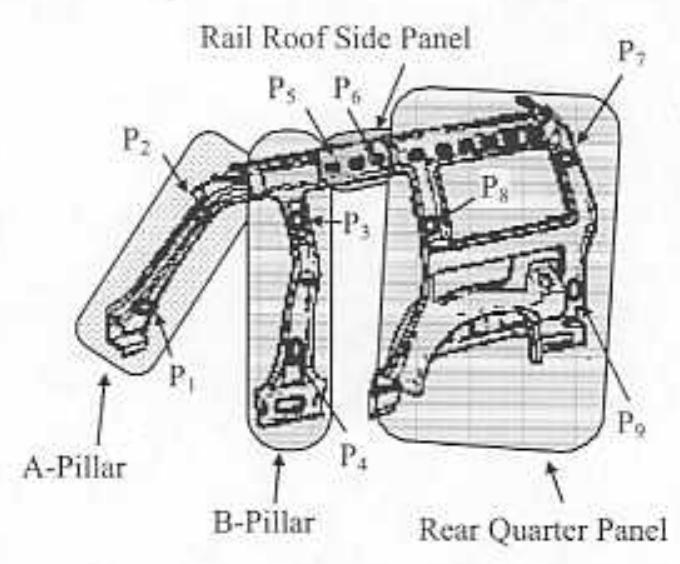

Figure 7. PLPs $\mathrm{P}_{1}-\mathrm{P}_{9}$ on the assembly

We propose four alternative process configuration schemes marked as $\mathrm{Cl}-\mathrm{C} 4$. Configuration $\mathrm{Cl}$ is currently used in one US automotive assembly plant and has been described in Section 2. Configuration $\mathrm{Cl}$ is used as the reference in our design evaluation. A major difference between other configurations $(\mathrm{C} 2, \mathrm{C} 3, \mathrm{C} 4)$ and $\mathrm{C} 1$ is that locator $\mathrm{P}_{9}$ is used to replace $P_{7}$ when the rear quarter panel is located on Station III. The fixture locating layout for each configuration is presented below with notations described in Section 2.

Configuration (C1): $\left\{\left\{\mathrm{P}_{1}, \mathrm{P}_{2}\right\},\left\{\mathrm{P}_{3}, \mathrm{P}_{4}\right\}\right\} \rightarrow\left\{\left\{\mathrm{P}_{1}, \mathrm{P}_{4}\right\},\left\{\mathrm{P}_{5}, \mathrm{P}_{6}\right\}\right\}_{\Perp} \rightarrow\left\{\left\{\mathrm{P}_{1}, \mathrm{P}_{6}\right\}:\left\{\mathrm{P}_{7}, \mathrm{P}_{8}\right\}\right\}_{111} \rightarrow\left\{\left\{\mathrm{P}_{1}, \mathrm{P}_{8}\right\}\right\}_{\mathrm{IV}}$ Configuration (C2): $\left.\left\{\left\{\mathrm{P}_{1}, \mathrm{P}_{2}\right\},\left\{\mathrm{P}_{3}, \mathrm{P}_{4}\right\}\right\}_{1} \rightarrow\left\{\left\{\mathrm{P}_{1}, \mathrm{P}_{4}\right\},\left\{\mathrm{P}_{5}, \mathrm{P}_{6}\right\}\right\}_{11} \rightarrow\left\{\mathrm{P}_{1}, \mathrm{P}_{6}\right\},\left\{\mathrm{P}_{8}, \mathrm{P}_{9}\right\}\right\}_{11} \rightarrow\left\{\left\{\mathrm{P}_{1}, \mathrm{P}_{9}\right\}\right\} / v$ Configuration (C3): $\left\{\left\{\mathrm{P}_{1}, \mathrm{P}_{2}\right\},\left\{\mathrm{P}_{4}, \mathrm{P}_{3}\right\}\right\}_{1} \rightarrow\left\{\left\{\mathrm{P}_{4}, \mathrm{P}_{2}\right\},\left\{\mathrm{P}_{5}, \mathrm{P}_{6}\right\}\right\}_{11} \rightarrow\left\{\left\{\mathrm{P}_{4}, \mathrm{P}_{6}\right\},\left\{\mathrm{P}_{8}, \mathrm{P}_{9}\right\}\right\}_{111} \rightarrow\left\{\left\{\mathrm{P}_{4}, \mathrm{P}_{9}\right\}\right\}_{1 \mathrm{~V}}$ Configuration (C4): $\left\{\left\{\mathrm{P}_{1}, \mathrm{P}_{2}\right\},\left\{\mathrm{P}_{4}, \mathrm{P}_{3}\right\}\right\}_{1} \rightarrow\left\{\left\{\mathrm{P}_{4}, \mathrm{P}_{2}\right\},\left\{\mathrm{P}_{5}, \mathrm{P}_{6}\right\}\right\}_{11} \rightarrow\left\{\left\{\mathrm{P}_{1}, \mathrm{P}_{6}\right\},\left\{\mathrm{P}_{8}, \mathrm{P}_{9}\right\}\right\}_{11} \rightarrow\left\{\left\{\mathrm{P}_{1}, \mathrm{P}_{9}\right\}\right\}_{1 \mathrm{~N}}$

In order to evaluate the different design configurations, a state space model is developed for the above four configurations, following methods presented in Jin and Shi (1999) and Ding et al. (2000a). The sensitivity-based design evaluation is then conducted following the three steps 
outlined in Section 3. During this case study, the weight coefficient matrix $\mathbf{W}$ is selected as an identity matrix, implying that all KPCs are treated with equal importance.

Step 0. State space modeling of the assembly process: In this SUV side panel assembly process, there are three assembly stations and one inspection station, i.e., $\mathrm{N}=4$. The fixture used on the inspection station is considered well maintained and calibrated with much higher repeatability than those on a regular assembly station. Thus, the input variation of fixture locators on the measurement station is neglected and the KCC deviation inputs from fixtures on three assembly stations, $\mathbf{P}(1), \mathbf{P}(2)$, and $\mathbf{P}(3)$, are included. The design evaluation is conducted to benchmark the three assembly stations. A state space model can be set up for this SUV side panel assembly process as

$$
\left\{\begin{array}{l}
\mathbf{X}(1)=\mathbf{B}(1) \mathbf{P}(1)+\xi(1) \\
\mathbf{X}(k)=\mathbf{A}(k-1) \mathbf{X}(k-1)+\mathbf{B}(k) \mathbf{P}(k)+\xi(k), k=2,3 \\
\mathbf{X}(4)=\mathbf{A}(3) \mathbf{X}(3)+\xi(4) \\
\mathbf{Y}=\mathbf{C X}(4)+\boldsymbol{\eta}
\end{array}\right.
$$

where A's, B's, and C can be obtained by substituting the parameters given in Tables 3 and 4 to Eqs. (38), (39), and (45) in Jin and Shi (1999). Due to the limited space, these system matrices of four different design configurations are included in Appendix II.

Step 1. System level design evaluation: The system sensitivity indices regarding all four process configurations are calculated and presented in Table 5.

Table 5. Process sensitivity index for $\mathrm{Cl}-\mathrm{C} 4$ process configuration

\begin{tabular}{|c|c|c|c|c|}
\hline & $\mathrm{C} 1$ & $\mathrm{C} 2$ & $\mathrm{C} 3$ & $\mathrm{C} 4$ \\
\hline$S_{0}$ & 6.14 & 3.33 & 3.26 & 3.13 \\
\hline
\end{tabular}

It is known that the lower the index value is, the better the robustness of a process design is. Comparing two sensitivity indices, we further quantify the significance of improvement (SOI) as

$$
\mathrm{SOI}=\frac{S_{o}^{\text {old }}-S_{o}^{\text {new }}}{S_{o}^{\text {old }}} \%
$$


SOI represents the percentage of KPC variation level change given a unit $\mathrm{KCC}$ variation input when a new process design configuration is compared to the original design configuration. A negative SOI means that the process sensitivity actually increases and the system robustness deteriorates. The value range of a SOI to be significant depends on the trade off between the saving from the quality improvement and the efforts in making the changes. The determination of quantitative SOI significant range could be only conducted where there are known the following relations: (a) statistical distributions of $\mathrm{KPC} / \mathrm{KCC}$ variables; (b) tolerance limits; and (c) variation/tolerance vs. cost (scrap, rework, warranty etc.). In the presented case study, based on our industrial knowledge and discussions with automotive engineers, we consider the SOI greater than $20 \%$ as significant, between $10 \%-20 \%$ as marginally significant, and less than $10 \%$ as insignificant.

One can calculate based on Table 5 that SOI $=45 \% \sim 49 \%$ when either one of $\mathrm{C} 2, \mathrm{C} 3$, and $\mathrm{C} 4$ is compared with $\mathrm{C}$, the current industrial configuration. It is concluded that the sensitivity level drops considerably when $\mathrm{P}_{9}$ is used to replace $\mathrm{P}_{7}$. The new configuration with $\mathrm{P}_{9}$ used significantly improve the system's robustness. The result suggests that $\mathrm{C} 1$, the design configuration currently used in industry, is not the optimal one with respect to the system robustness to dimensional variations. However, the SOI between any two of the other three process designs using $\mathrm{P}_{9}$ (options $\mathrm{C} 2, \mathrm{C} 3$, and $\mathrm{C} 4$ ) is smaller than $6 \%$. Therefore their differences are not significant. The fourth scheme (C4) yields the lowest $S_{o}$ value among the four process configurations. The value of SOI equals $49.0 \%$ when $\mathrm{C} 4$ is compared with $\mathrm{C} 1$, which corresponds to a $49.0 \%$ decrease in KPC variation level under the same condition of $\mathrm{KCC}$ variation input. Hence, it is recommended that the current process design should be replaced by Configuration $\mathrm{C} 4$.

Step 2: Station level design evaluation: Let us further study the station sensitivity of the fourth configuration (C4) to identify which station causing the biggest contribution to the KPC variation. Sensitivity indices for three stations are shown in Table 6. 
Table 6. Station sensitivity index for Configuration C4

\begin{tabular}{|c|c|c|c|}
\hline & Station I & Station II & Station III \\
\hline$S_{k}$ & 2.94 & 1.69 & 3.01 \\
\hline
\end{tabular}

The percentage of variation contribution (PVC) from station $k$ can be calculated using the following index

$$
\mathrm{PVC}_{k}=\frac{S_{k}}{\sum_{k=1}^{N} S_{k}} \%
$$

One can find that $\mathrm{PVC}_{3}=39.4 \%, \mathrm{PVC}_{1}=38.5 \%$, and $\mathrm{PVC}_{2}=22.1 \%$. The third station is the most critical station with the highest sensitivity and PVC value. Station I also has remarkable contribution to the KPC variation. Stations I and III together account for $77.9 \%$ contribution in the KPC variation level. Station II has the lowest station sensitivity and the smallest PVC value. It would be the designer's highest priority to investigate the design layouts of Stations I and III.

Step 3. Fixture level design evaluation: Finally, the fixture sensitivity index is computed for evaluation. At each station, two parts/subassemblies are positioned by four independent locating pins. The total 12 indices are shown in Table 7.

Table 7. Fixture sensitivity index for Configuration $\mathrm{C} 4$

\begin{tabular}{|l|c|c|c|}
\hline & Station I & Station II & Station III \\
\hline Locator I & 2.38 & 1.50 & 2.03 \\
\hline Locator 2 & 1.37 & 0.69 & 0.75 \\
\hline Locator 3 & 2.18 & 0.65 & 2.68 \\
\hline Locator 4 & 0.75 & 0.56 & 1.09 \\
\hline
\end{tabular}

From the above table, it is found that all locators at Station II are not the major variation inputs. Stations I and III include some critical variation sources. Locators 1 and 3 (4-way locators) at Stations I and III cause the largest variations in the final assembly if the input variations have the same magnitude. The variation reduction and design effort should first be focused on Stations I and III to reduce the sensitivity of these two 4-way locators.

A numerical simulation software such as VSA can be used to obtain the sensitivity indices by performing Monte Carlo simulations. As discussed in Section 3, it is difficult and time- 
consuming to compute MIMO-type of indices such as $S_{k}$ and $S_{0}$ by using VSA. Thus, the VSA software is only used to obtain the fixture level sensitivity index $S_{k p}$. An identical assembly process as presented in the case study is modeled using the VSL language and the numerical variation model is generated in the VSA. A normal variation source with $3 \sigma=1$ is assigned to one fixture locator each time, and 5000-run Monte Carlo simulations are then conducted. The sensitivity index is computed by dividing the KPC variation by the input source's variance. The results are compared with those values in Table 7 , which are calculated from design parameters using analytical formulations. The comparison is shown in Fig. 8, where it can be observed very good consistency between the analytical and numerical calculation of fixture level sensitivity index. The maximum difference is less than $3.2 \%$.

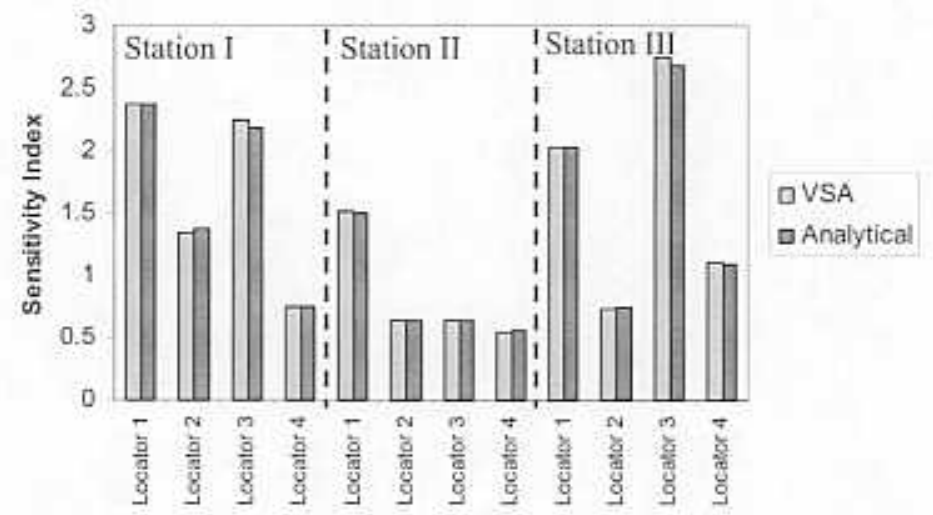

Figure 8. Comparison of sensitivity index from VSA and analytical approach

\section{SUMMARY}

In a multi-station assembly process, the dimensional variation is caused by the fixture elements on every station and accumulated on the final product. The process/product design greatly affects the dimensional quality of product. The effective way to describe the system behavior in response to variation inputs is a critical issue in the design of multi-station assembly processes. Well-defined process performance indicator can help designers to benchmark different 
design alternatives and select a better design configuration to make the whole process/product design robust to variation sources.

This paper develops a group of hierarchical sensitivity indices based on the developed state space model of a multi-station assembly process. Engineering information regarding process design, such as fixture locating layout and station-to-station locating layout change, are incorporated in the model so that the three-level indices can describe the multistage system's response to the variation inputs in terms of the critical design parameters. This sensitivity-based design evaluation can be conducted in three steps: (1) at the system level (index $S_{0}$ ) by evaluating and selecting assembly process configurations, (2) at the station level (index $S_{k}$ ) by identifying the critical station(s) in an assembly process, and (3) at the fixture level (index $S_{k p}$ ) by isolating the critical elements of fixture.

Design evaluation by using these analytical sensitivity indices has a number of advantages over numerical methods such as the VSA software. First, it is numerically efficient because the time-consuming Monte Carlo simulation can be avoided. Second, the new approach provides MIMO-type of sensitivity index, which is very difficult to realize using numerical methods. Third, these analytical models and sensitivity expressions allow for the further optimization of design. In contrast, the numerical-based methods are very limited in finding the optimal solution for process design.

The proposed approach was implemented for the SUV side panel assembly process. The case study demonstrates the concept and procedure of the sensitivity-based design evaluation. As a result of the proposed methodology, the manufacturing system robustness can be greatly improved ( $49 \%$ in the presented case) as compared to the current industrial practice if the appropriate design configuration is selected. The station level and fixture level sensitivity analysis helps designers to isolate the critical station and fixture elements, respectively. Although the study is conducted in the context of assembly process, the sensitivity-based design evaluation is fairly general due to the generic state space formulation. It can be applied to other multistage 
manufacturing processes such as machining and semiconductor processes so long as the variation propagation in those processes is modeled in the same state space framework.

\section{ACKNOWLEDGEMENT}

This research is partially supported by The NSF CAREER Award DMI 9624402 , DaimlerChrysler Corporation, and the state of Wisconsin's IEDR program.

\section{REFERENCES:}

1. Agrawal, R., Lawless, J.F. and Mackay, R.J., 1999, "Analysis of Variation Transmission in Manufacturing Processes - Part II," Journal of Quality Technology, 31, pp. 143-154.

2. Antonsson, E. K. and Otto, K. N., 1995, "Imprecision in Engineering Design," ASME Journal of Mechanical Design, 117B, pp. 25 - 32.

3. Cai, W, Hu, S. J., and Yuan J. X., 1997, "A Variational Method of Robust Fixture Configuration Design for 3-D Workpieces," ASME Journal of Mamufacturing Science and Engineering, 119, pp. $593-602$.

4. Ceglarek, D. and Shi, J., 1995, "Dimensional Variation Reduction for Automotive Body Assembly," Manufacturing Review, 8, No. 2, pp. $139-154$.

5. Ceglarek, D. and Shi, J., 1998, "Design Evaluation of Sheet Metal Joints for Dimensional Integrity," ASME Joumal of Mantfacturing Science and Engineering, 120, pp. 452 - 460.

6. Ceglarek, D., Shi, J., and Wu, S.M., 1994, "A Knowledge-Based Diagnostic Approach for the Launch of the Auto-Body Assembly Process," ASME Journal of Engineering for Industry, 116, pp. $491-499$.

7. Chen W., Allen J.K, Tsui, K-L, Mistree, F., 1996, "A Procedure for Robust Design: Minimizing Variations Caused by Noise Factors and Control Factors," ASME Journal of Mechanical Design, 118, pp. 478 - 485 . 
8. Chen, C.T., 1984, Linear System Theory and Design, Harcourt Brace Jovanovich Inc. Oriando, FL 32887.

9. Cunningham, T. W., Matripragada, R., Lee, D. J, Thornton, A. C., and Whitney D. E., 1996, "Definition, Analysis, and Planning of a Flexible Assembly Process," Proceedings of 1996 Japan/USA Symposium on Flexible Automation, 2, pp. 767 - 778.

10. Ding, Y., Ceglarek, D., and Shi, J., 2000a, "Modeling and Diagnosis of Multistage Manufacturing Processes : Part I State Space Model," Proceedings of the 2000 Japan/USA Symposium on Flexible Automation, July 23-26, Ann Arbor, MI, 2000JUSFA-13146.

11. Ding. Y., Jin, J., Ceglarek, D., and Shi, J., 2000b, "Process-oriented Tolerance Synthesis of Multistage Manufacturing Systems," Proceeding of the 2000 ASME IMECE, MED-Vol. 11, Nov. 5-10, Orlando, FL, pp. $15-22$.

12. Jin, J. and Shi, J., 1999, "State Space Modeling of Sheet Metal Assembly for Dimensional Control," ASME Journal of Mamufacturing Science \& Engineering, 121, pp. 756 - 762.

13. Kazmer, D. and Roser, C., 1999, "Evaluation of Product and Process Design Robustness," Research in Engineering Design, 11, pp. 22 - 30 .

14. Lawless, J.F., Mackay, R. J. and Robinson, J.A., 1999, "Analysis of Variation Transmission in Manufacturing Processes - Part I," Journal of Quality Technology, 31, pp. 131 - 142.

15. Mantripragada, R. and Whitney, D. E., 1999, "Modeling and Controlling Variation Propagation in Mechanical Assemblies Using State Transition Models," IEEE Trans. On Robotics and Automation, 15, pp.124-140.

16. Montgomery, D. C., 1996, Introduction to Statistical Quality Control, $3^{\text {rd }}$ edition, John Wiley \& Sons, Inc., New York.

17. Parkinson A., 1995, "Robust Mechanical Design Using Engineering Models," ASME Journal of Mechanical Design, 117B, pp. 48 - 54.

18. Parkinson A., Sorensen, C, and Pourhassan, N., 1993, "A General Approach for Robust Optimal Design," ASME Journal of Mechanical Design, 115, pp. $74-80$. 
19. Shiu, B., Ceglarek, D., and Shi, J., 1996, "Multi-Station Sheet Metal Assembly Modeling and Diagnostics," NAMRI/SME Transactions, XXIV, pp. 199-204.

20. Soderberg, R. and Carlson, J. S., 1999, "Locating Scheme Analysis for Robust Assembly and Fixture Design," Proceedings of the 1999 ASME Design Engineering Technical Conferences, September 12-15, 1999, Las Vegas, Nevada.

21. Suri, R. and Otto, K., 1999, "Variation Modeling for a Sheet Stretch Forming Manufacturing System," Annals of CIRP, 48, pp. $397-400$.

22. Suri, R., Painter, C. and Otto, K., 1999, "Process Capability to Guide Tolerancing in Manufacturing Systems," Transactions of NAMRI/SME, XXVII, pp. 227 - 232.

23. Taguchi, G., 1986, Introduction to Quality Engineering, Asian Productivity Organization, Tokyo, Japan.

24. Thornton, A. C., 1999a, "A Mathematical Framework for the Key Characteristic Process," Research in Engineering Design, 11, pp. 145 - 157.

25. Thornton, A. C., 1999b, "Variation Risk Management Using Modeling and Simulation," ASME Journal of Mechanical Design, 121, pp. 297-304.

26. Thornton, A.C., 2000, "Quantitative Selection of Variation Reduction Plans," ASME Journal of Mechanical Design, 122, pp. 185-193.

27. VSA, 1998, VSA-3D Release 12.5 User Manual, Variation System Analysis, Inc., 300 Maple Park Boulevard, St. Clair Shores, MI 48081.

28. Wang, M. Y., 1999, "An Optimum Design Approach to Fixture Synthesis for 3D Workpieces," Transactions of NAMRI/SME, XXVII, pp. 209 - 214.

29. Whitney, D.E., Gilbert, O., and Jastrzebski, M., 1994, "Representation of Geometric Variations Using Matrix Transforms for Statistical Tolerance Analysis in Assemblies," Research in Engineering Design, 6, pp. $191-210$.

30. Wood, K. L, and Antonsson, E. K., 1989, "Computations with Imprecise Parameters in Engineering Design: Background and Theory," ASME Journal of Mechanisms, Transmissions, and Automation in Design, 111, pp. 616-625. 


\section{APPENDIX I: PROOF OF LEMMA IN SECTION 3}

Proof. If the $\mathrm{KCC}$ variation inputs are uncorrelated, then the covariance matrix $\mathrm{K}_{\mathrm{P}}(k)$ are diagonal for all $k$ stations. Denote $\mathrm{K}_{\mathrm{P}}(k)$ as

$$
\mathbf{K}_{\mathrm{p}}(k)=\left[\begin{array}{cccc}
\sigma_{k 1}^{2} & & & \\
& \sigma_{k z}^{2} & & \\
& & \ddots & \\
& & & \sigma_{i m, j}^{2}
\end{array}\right]
$$

Then, from Eq. (8)

$$
\mathbf{K}_{\mathrm{Y}}=\sum_{k=0}^{N}\left[\begin{array}{cccc}
\mid & \mid & & \mid \\
\gamma_{1}(k) & \gamma_{2}(k) & \cdots & \gamma_{m_{2}}(k) \\
& \mid & & \mid
\end{array}\right] \cdot\left[\begin{array}{cccc}
\sigma_{\ell 1}^{2} & & & \\
& \sigma_{k 2}^{2} & & \\
& & \ddots & \\
& & & \sigma_{i m_{1}}^{2}
\end{array}\right] \cdot\left[\begin{array}{cccc}
\mid & \mid & & \mid \\
\gamma_{1}(k) & \gamma_{2}(k) & \cdots & \gamma_{m_{y}}(k) \\
\mid & \mid & & \mid
\end{array}\right]^{\top}
$$

Furthermore,

$$
\mathbf{K}_{\mathrm{Y}}=\sum_{k=1}^{N}\left[\begin{array}{cccc}
\mid & \mid & & \mid \\
\gamma_{1}(k) & \gamma_{2}(k) & \cdots & \gamma_{m_{3}}(k) \\
\mid & \mid & & \mid
\end{array}\right] \cdot\left[\begin{array}{cccc}
\mid & \mid & & \mid \\
\sigma_{k 1}^{2} \gamma_{1}(k) & \sigma_{k 2}^{2} \gamma_{2}(k) & \cdots & \sigma_{k \mathrm{~m}}^{2} \gamma_{m_{2}}(k) \\
\mid & \mid & & \mid
\end{array}\right]^{\top}
$$

If the diagonal elements of $\mathbf{K}_{Y}$ are extracted and arranged into a vector, we have

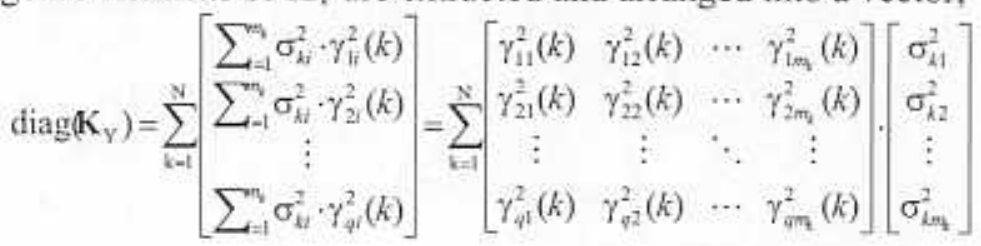

where $\operatorname{diag}(\cdot)$ extracts the diagonal elements from a matrix and forms a column vector. According to the definition of $\left[\gamma^{2}(k)\right]$ and $\sigma_{k}^{2}$, and also be aware of $\operatorname{diag}\left(\mathrm{K}_{\mathrm{Y}}\right)=\sigma_{\text {oxpmut }}^{2}$, the Lemma is proved true.

Q.E.D.

\section{APPENDIX II: SYSTEM MATRICES IN THE CASE STUDY}

\section{1 System matrices of configuration C1}

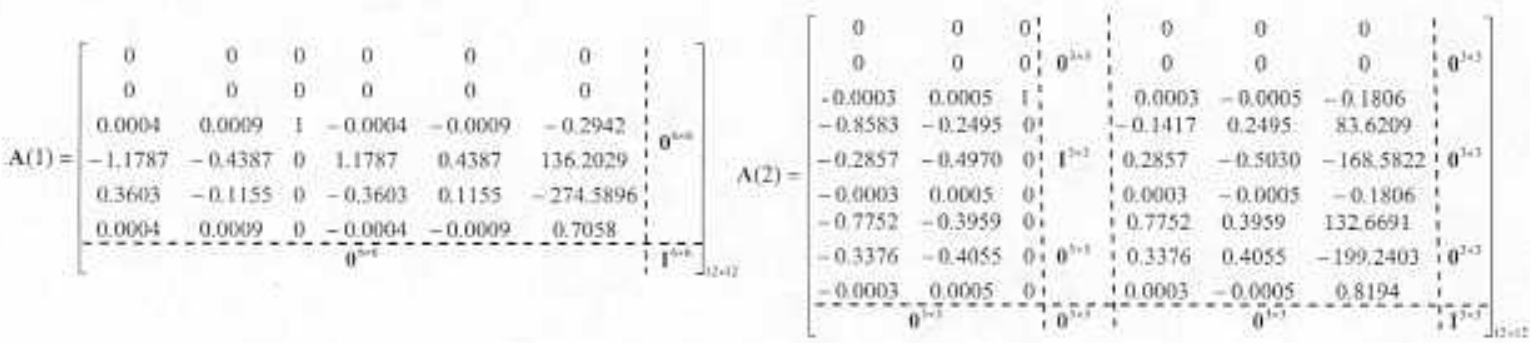



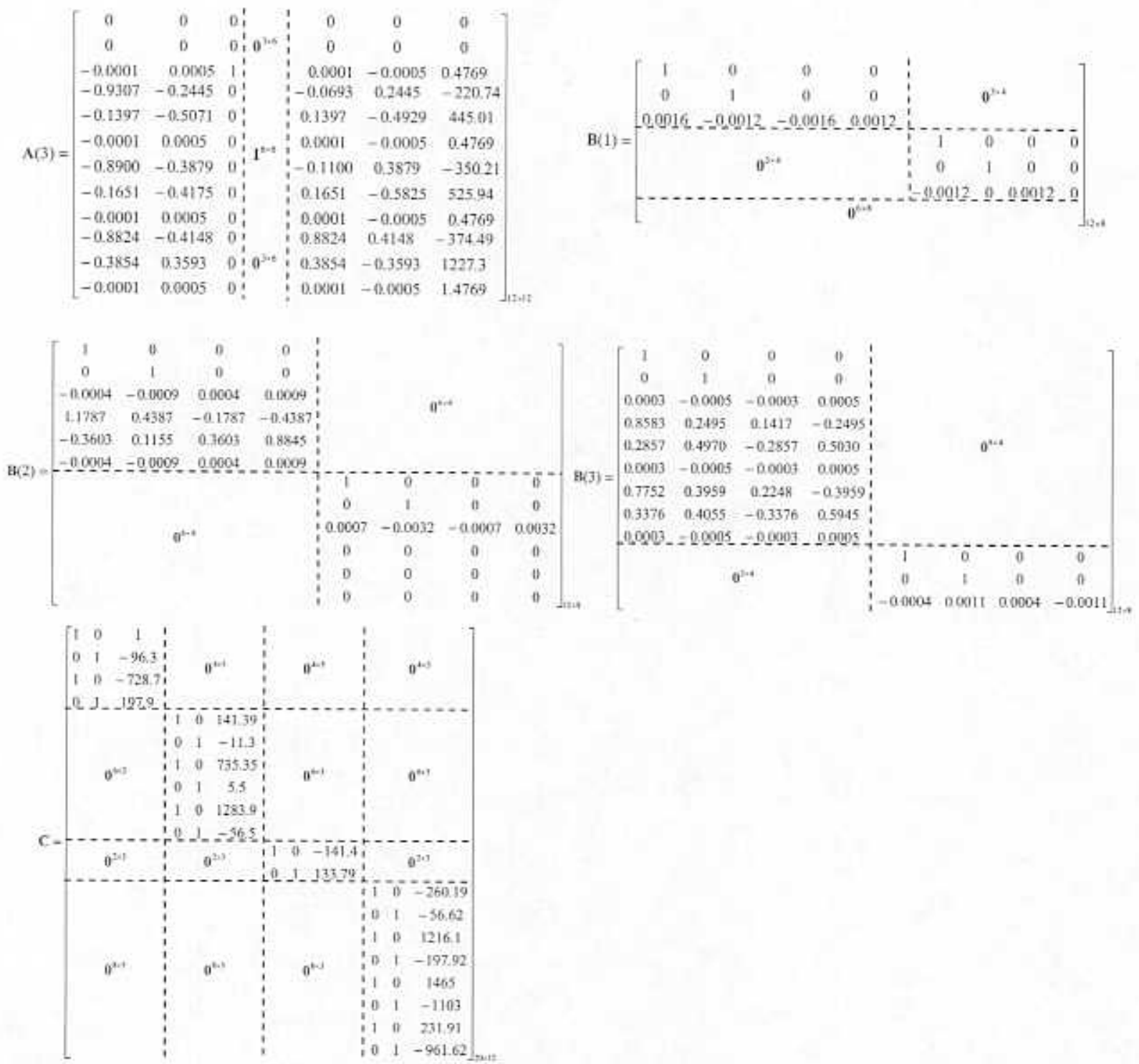

\section{II.2 System matrices of configuration C2}

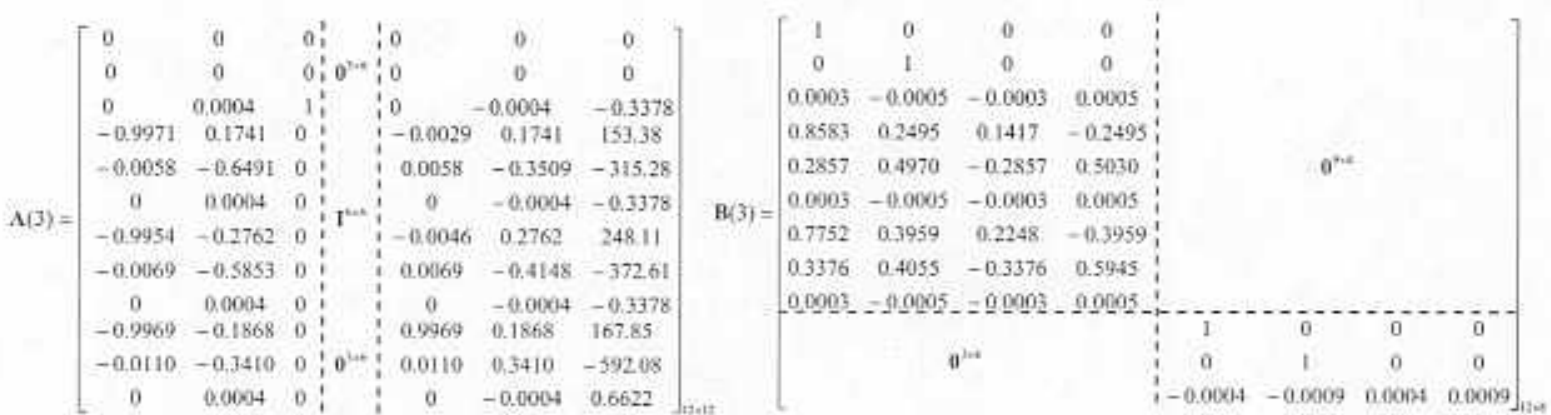




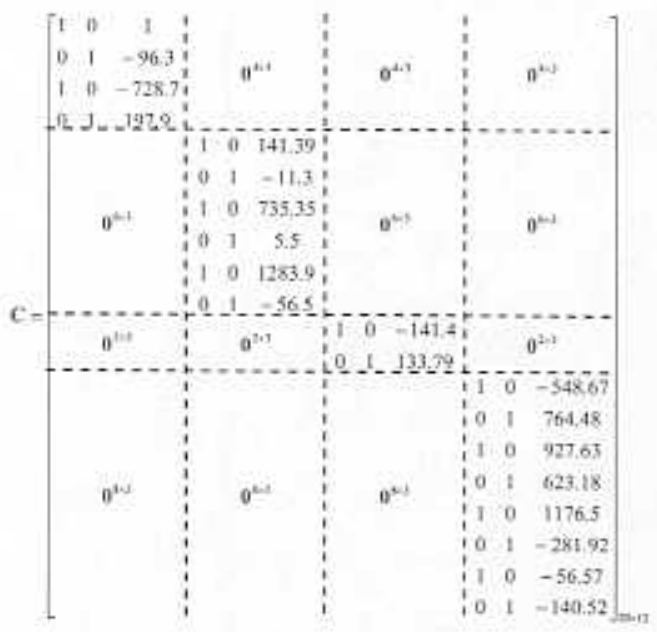

Matrices $\mathbf{A}(1), \mathbf{A}(2), \mathbf{B}(1), \mathbf{B}(2)$ are the same as those of configuration $\mathrm{Cl}$.

\section{II.3 System matrices of configuration C3}

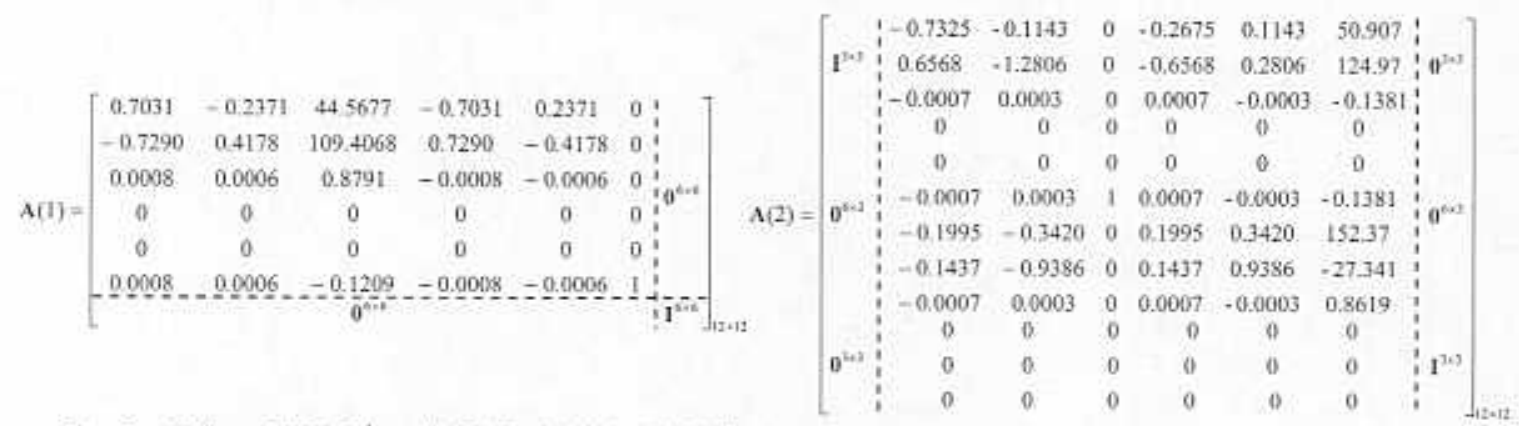

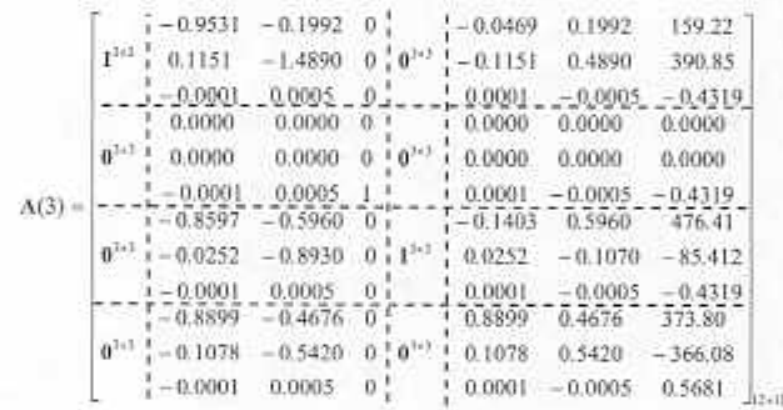



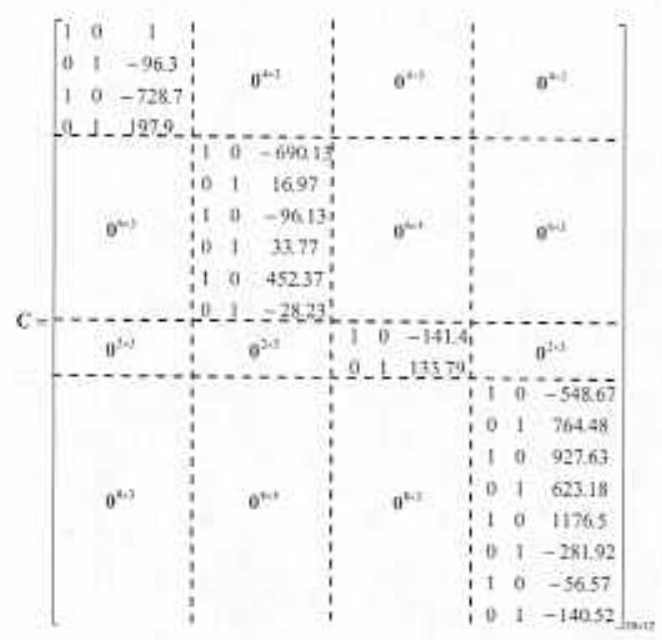

II.4 System matrices of configuration C4

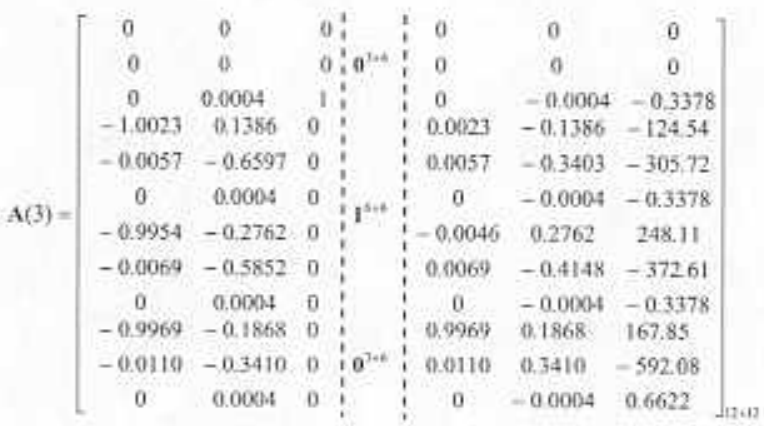

Matrices $\mathbf{A}(1), \mathbf{B}(1), \mathbf{B}(2), \mathbf{C}$ are the same as those of configuration $\mathrm{C} 3$. 